\title{
International medical electives undertaken by Australian medical students: current trends and future directions
}

\begin{abstract}
lain R Law
BSC, MSC Medical Student ${ }^{1}$

Paul S Worley MBBS, PhD, FACRRM Dean of Medicine

Freya J Langham

BMedSci(Hons)

Global Health Officer2

1 Flinders University Adelaide, SA

2 Australian Medical Students' Association,

Canberra, ACT.

iain.law@

flinders.edu.au
\end{abstract}

MJA 2013; 198: 324-326 doi: 10.5694/mjal2.11463 $\mathrm{n}$ response to the increasing interest among medical students and junior doctors in studying and practising medicine abroad, the Medical Journal of Australia recently published A guide to working abroad for Australian medical students and junior doctors. ${ }^{1}$ It is in the context of increasing interest in global health ${ }^{2}$ and in the spirit of supporting young medical professionals that this study examines international medical electives (IMEs), specifically the number of Australian medical students undertaking them, and the support provided to those students by Australian medical schools.

Electives are a compulsory component of all medical curricula in Australia. They are usually undertaken during senior clinical years over 2 to 8 weeks, either in Australia or overseas, in both high- and low-resource settings. Consistent with increasing interest in global health, IME rates have been found to be high in the United Kingdom and increasing in the United States..$^{2,3}$

Many benefits of IMEs have been described. Students report less dependence on technology; improved clinical, diagnostic and communication skills; better knowledge of tropical diseases and immigrant health; and better understanding of prevention, primary care and public health. 2,4 Participation in IMEs influences students' career choices towards primary care specialties, graduate education in public health, and working with underserved populations. ${ }^{5,6}$ In contrast, the potential benefits to communities hosting students on medical electives have received little attention and are poorly understood. ${ }^{4}$

IMEs also present potential risks and harms to both the student and the host community. Risks to the student include transmission of disease, needlestick injuries, traffic accidents, crime-related injuries, and mental health problems. ${ }^{7}$ Potential harms to host communities, particularly in developing countries, emerge from a power imbalance between visiting students and host

Abstract

Objectives: To estimate the proportion of students in Australian medical schools who undertake international medical electives (IMEs), particularly in developing countries, and to ascertain which medical schools provide predeparture training and postelective debriefing.

Design, setting and participants: Extraction of data on the number of students undertaking electives from the Medical Schools Outcomes Database (MSOD) for the years 2006 to 2010; and interviews with the directors of each medical school in Australia in May to July 2012 to ascertain the availability of predeparture training and postelective debriefing.

Main outcome measures: The proportion of medical students undertaking IMES overall and within developing countries and the proportion of medical schools with optional and mandatory predeparture training and postelective debriefing.

Results: Fifty-three per cent of graduate-entry (GE) program students and 35\% of high-school entry (HSE) program students undertook IMEs. Fifty-nine per cent of electives undertaken by GE program students were in developing countries, compared with $56 \%$ for HSE program students. Predeparture training was offered by 12 of the 16 Australian medical schools, but it was mandatory in only six. Only eight schools offer postelective debriefing.

Conclusions: A large proportion of Australian medical students undertake IMEs in developing countries. However, a considerable proportion of students do not undertake formal preparation for, or reflection on, their experiences. Predeparture training and postelective debriefing should be scaled up across Australian medical schools to provide students with the guidance and support to maximise the benefits and minimise risks associated with undertaking IMEs in developing countries.

communities, and the potential for students focused on learning objectives to compromise patient care and community wellbeing. ${ }^{8}$ As a result, IMEs may falsely raise expectations, impose burdens on local human resources, and impede continuity of and access to care, ultimately compromising equity and sustainability. ${ }^{9}$

Predeparture training and post-elective debriefing can provide students with guidance and support to reduce potential harms and maximise the benefits of IMEs. ${ }^{10}$ Predeparture training prepares students with the tools to manage the ethical, cultural and logistical challenges they may encounter. Postelective debriefing provides a forum for students to discuss and explore any issues that arose, consolidate learning, and encourage the development of students as responsible doctors.

At present no study has evaluated the proportion of Australian medical students undertaking IMEs and the support offered by Australian medical schools. This study set out to remedy this evidence gap.

\section{Methods}

The Medical Schools Outcomes Database (MSOD) is a national initiative for longitudinal tracking of medical students through medical school and into prevocational and vocational training; ${ }^{11}$ it began collecting data nationally in 2006. In May 2012, we obtained data from the MSOD covering the period 1 January 2006 to 31 December 2010 to establish the number of students who undertook IMEs. Students consent to participate in the MSOD project in their first year of medical school, and are subsequently included in annual follow-ups. Therefore, the 2006 data only include Year 1 students, the 2007 data include students in Years 1 and 2, the 2008 data include students in Years 1, 2 and 3, and so on. As a result, four cohorts of students within the dataset had graduated and were used to estimate the total proportion of medical students who undertake at least one IME during their degree. Students who took more than one IME were counted once, and we estimated cohort size using the total number of students who 
were registered in the final year of their medical course.

We also conducted structured interviews with academic staff from 16 of the 19 Australian medical schools (those at the University of Notre Dame in Sydney and Fremantle have different curriculums and are considered as separate schools in this study). Data were collected from Australian medical schools between May and July 2012 and reflect the program status at that time.

We divided medical education programs into high-school entry (HSE) programs (5- or 6-year programs that admit students after they complete high school, although some students may have a prior degree) and graduate-entry (GE) programs (4- or 5-year programs that require students to have a prior undergraduate degree). Programs with a mid-year intake (ie, 4.5-year programs) were treated as 5-year programs.

We collected data on predeparture training and postelective debriefing independently from each medical school in Australia. Data were collected in cooperation with the Australian Medical Students'Association (AMSA) and the AMSA Global Health (AGH) Committee, which comprises student representatives from every medical school in Australia. AGH Committee representatives were provided with letters of introduction, information sheets, consent forms, interview scripts, and response forms. Representatives were asked to gain consent and conduct an interview with the director of their medical program.

The income status of countries where students undertook electives was based on the World Bank Atlas Method. Lower- or middle-income countries included countries with a gross national income per capita of less than US\$12275. ${ }^{12}$ For the purposes of this analysis, states that remain protectorates were placed in the same category as the protecting country.

Ethics approval for release of MSOD data was granted by the Medical Deans Australia and New Zealand Research and Scientific Advisory Committee (SA-2012-003). Ethics approval for data collection from medical schools was granted by the Social and Behavioural Research Ethics Committee at Flinders University (Project No: 5561).
Students who both commenced and graduated from an Australian medical school during 2006-2010 and who undertook international medical electives (IMEs)

\begin{tabular}{lccc} 
Variable & $\begin{array}{c}\text { All students } \\
(n=2101)\end{array}$ & $\begin{array}{c}\text { HSE program } \\
\text { students } \\
(n=383)\end{array}$ & $\begin{array}{c}\text { GE program } \\
\text { students } \\
(n=1718)\end{array}$ \\
\hline Students undertaking an IME & $1044(49.7 \%)$ & $135(35.3 \%)$ & $909(52.9 \%)$ \\
IME in a lower- or middle-income country & $613(58.7 \%)$ & $75(55.6 \%)$ & $538(59.2 \%)$ \\
IME in country of birth* & $110(10.5 \%)$ & $21(15.6 \%)$ & $89(9.8 \%)$ \\
\hline
\end{tabular}

GE = graduate-entry. $\mathrm{HSE}=$ high-school entry.

* International students.

\section{Results}

\section{MSOD data}

Participation in the MSOD over our study period averaged $88 \%$ of students enrolled at Australian medical schools. ${ }^{11}$ The four cohorts in our study included the 5-year HSE program cohort that commenced in 2006, and three GE cohorts (the 4- and 5-year program cohorts that commenced in 2006, and the 4-year program cohort that commenced in 2007). Our findings on students in these cohorts who undertook IMEs are summarised in the Box.

\section{Medical school interviews}

Currently, 12 of the 16 Australian medical schools interviewed offer some form of predeparture training. However, in only six of these schools is predeparture training mandatory. The average duration of predeparture training is 4.7 (SD, 4.22) hours. By comparison, eight schools offer some form of postelective debriefing. However, in only three schools is this mandatory. The average duration of postelective debriefing is 1.2 (SD, 0.91) hours.

\section{Discussion}

Our findings show that a significant proportion of Australian medical students undertake IMEs, and that more than half do so in developing countries.

Our estimates show that a greater proportion of Australian medical students undertake IMEs compared with US medical students. The estimated proportion of US medical students who undertook IMEs in 2007 was about $30 \%$, and all of these were GE program students. ${ }^{13}$ By contrast, a study from the UK (where most medical schools offer HSE programs) estimates that $90 \%$ of medical students undertake IMEs, with $44 \%$ of them doing so in developing countries. ${ }^{3}$ While a much smaller proportion of Australian GE and HSE students undertake IMEs than UK students, a greater proportion of them do so in developing countries.

Considering that a significant proportion of Australian medical students undertook electives in developing countries, it is concerning that predeparture training and postelective debriefing are not offered to all students, and that what is offered is not always compulsory. However, improvement is achievable. In 2008, only 11 of the 17 Canadian medical schools offered predeparture training, and in only six of these was such training mandatory. ${ }^{14}$ By 2010 , this had increased to 16 out of 17 schools offering predeparture training, with 11 making it mandatory. ${ }^{15}$ A similar transformation in Australia is both necessary and possible.

Our study was limited by the lack of data forYear 6 HSE students, relatively small cohort sizes in senior years, and less than full participation in the MSOD program. Nonetheless, our data provide a foundation for further research into the content of predeparture training and postelective debriefing and financial support offered by Australian medical schools, as well as the benefits and acceptability of predeparture training and postelective debriefing programs to students. We encourage medical schools to scale up predeparture training and postelective debriefing that adequately prepare students to undertake safe and ethical electives. We also recommend that a similar study be repeated in 3 to 5 years to evaluate progress in predeparture training and postelective debriefing.

Acknowledgements: The research on which this publication is based used data provided by the Medical Schools Outcomes Database and Longitudinal Tracking Project, Medical Deans Australia and New Zealand. We thank the medical students, graduates and doctors who participated. The MSOD project is possible due to funding from Health Workforce Australia (2011 onwards) and the Australian Government Department of Health and Ageing (2004-2011). We thank AMSA for its cooperation with this project and the committed efforts of the 
student representatives of the AGH Committee for their role in data collection.

Competing interests: No relevant disclosures.

Received 25 Sep 2012, accepted 31 Jan 2013.

1 Parker J, Mitchell R, Mansfield S, et al. A guide to working abroad for Australian medical students and junior doctors. Med J Aust 2011; 194 (12 Suppl): eSl-eS95.

2 Drain PK, Primack A, Hunt DD, et al. Global health in medical education: a call for more training and opportunities. Acad Med 2007; 82 226-230.

3 Miranda JJ, Yudkin JS, Willott C. International health electives: four years of experience. Trave Med Infect Dis 2005; 3: 133-141.

4 Mutchnick IS, Moyer CA, Stern DT. Expanding the boundaries of medical education: evidence for cross-cultural exchanges. Acad Med 2003; 78 (10 Suppl): S1-S5.

5 Jeffrey J, Dumont RA, Kim GY, Kuo T. Effects of international health electives on medical student learning and career choice: results of a systematic literature review. Fam Med 2011; 43: 21-28.

6 Godkin M, Savageau J. The effect of medical students' international experiences on attitudes toward serving underserved multicultural populations. Fam Med 2003; 35: 273-278.

7 Tyagi S, Corbett S, Welfare M. Safety on elective: a survey on safety advice and adverse events during electives. Clin Med 2006; 6: 154-156.

8 Pinto AD, Upshur REG. Global health ethics for students. Dev World Bioeth 2009; 9: 1-10.

9 Dickson M, Dickson G. Volunteering: beyond an act of charity. J Can Dent Assoc 2005; 71: 865-869.

10 Hanson L, Harms S, Plamondon K. Undergraduate international medical electives: some ethical and pedagogical considerations. J Stud Int Educ 2011; 15: 171-185.

11 Beilby J, Glasgow N, Landau L, et al; MSOD \& Longitudinal Tracking Project Board. Medical Schools Outcomes Database (MSOD) and Longitudinal Tracking Project. Stage 2 final report, July 2005 - June 2010. Sydney: Medical Deans Australia and New Zealand Incorporated
2010. http://www.medicaldeans.org.au/wpcontent/uploads/MSOD-Stage-2-Final-ReportFINAL.pdf (accessed Jul 2012).

12 World Bank. World development indicators 2012. Washington, DC: The World Bank, 2012. http://data.worldbank.org/data-catalog/worlddevelopment-indicators/wdi-2012 (accessed Jul 2012).

13 Association of American Medical Colleges. GQ medical school graduation questionnaire. All schools summary report. Final 2010. Washington DC: Association of American Medical Colleges, 2010. https://www.aamc.org/download/140716/ data/2010_gq_all_schools.pdf (accessed Jul 2012).

14 Izadnegahdar R, Correia S, Ohata B, et al. Global health in Canadian medical education: current practices and opportunities. Acad Med 2008 83: 192-198.

15 Anderson KC, Slatnik MA, Pereira I, et al. Are we there yet? Preparing Canadian medical students for global health electives. Acad Med 2012; 87 : 206-209. 